\title{
Voice Onset Time (VOT) and Vowel Duration
}

\author{
YohanaVeniranda \\ English Language Education Study Program \\ Sanata Dharma University \\ veniranda02@yahoo.com
}

\begin{abstract}
This study investigates the effects of voicing of a preceding and following plosive on the Voice Onset Time (VOT) and vowel duration. The data consist of words with CVC segments, with the four groups of samples that represent both voiced and voiceless plosives, both for the ones following and preceding the vowels. The preliminary hypothesis is that voicing of following plosives affects the length of the vowels, indicated by the vowel duration, and VOT is affected by the voicing of the preceding plosives, not the following plosives. To compare the effects of voicing on the lengths of the vowel duration and VOT, the sound files are analyzed using the Praat program.

The results of this study show that the voicing of the following plosives affects the vowel duration, while the voicing of the preceding plosives does not affect the vowel duration. The results also show that it is the voicing of the $C_{1}$ plosives that affect the VOT. The word-ending plosives do not affect the VOT of the preceding plosives.This study is on English vowel duration and VOT affected by the following and preceding stops. A further study can be done to compare the results of the effects with another language.
\end{abstract}

Keywords: VOT, vowel duration, the Praat program.

\section{INTRODUCTION}

This study investigates the effects of voicing of a preceding and following plosive on the Voice Onset Time (VOT) and vowel duration. The data consist of words with CVC segments, with the fourgroups of samples that represent both voiced and voiceless plosives, both for the ones following and preceding the vowels. The preliminary hypothesis is that voicing of following plosives affects the length of the vowels, indicated by the vowel duration, and VOT is affected by the voicing of the preceding plosives, not the following plosives. To compare the effects of voicing on the lengths of the vowel duration and VOT, the sound files are analyzed using the Praat program.

\section{A. METHODS}

a. The Data

The data consist of the following sound files:

1) Four sound files, each file consists of 8 test words. The test words are in the carrier sentence "The word is...." There is one token of each word. The words, which have the segments of CVC, have been grouped in the following categories. Here are the words in this study:

a) $\mathrm{C}_{\text {[-voice] }} \mathrm{V} \mathrm{C}_{\text {[-voice] }}$ : pat, pot, cot, putt, talk, puck, tuck, pick.

b) $\mathrm{C}_{[\text {-voice] }} \mathrm{V}_{\text {[+voice] }}$ pad, pod, cod, pud, tog, pug, tug, pig.

c) $\mathrm{C}_{[+ \text {voice] }} \mathrm{V} \mathrm{C}_{\text {[-voice] }}$ : bat, bought, got, but, dock, buck, duck, bic.

d) $\mathrm{C}_{[+ \text {voice] }} \mathrm{V} \mathrm{C}_{[+ \text {voice] }}$ : bad, bod, god, bud, bug, dug, big. 
2) Four sound files, each file consists of one test word. There are 10 tokens of each word. The test word is in the carrier sentence "The word is...." In these four sound files, there are four test words that represent each of the 4 CVC categories, and the vowel segment is the same. In this study, the words aretuck, tug, duck, dug. The recording is done using the sound recorder in the Praat program, recorded as mono sound, and the sampling frequency is set at $8,000 \mathrm{~Hz}$. The sound files are saved as WAV files.

\section{b. The Analysis}

The calculation of the means and standard deviation of the vowel duration and VOT is done by grouping the consonants that follow the vowels into voiced and voiceless and that precede the vowels into voiced and voiceless. In the analysis, the abbreviation of $\mathrm{C} 1$ refers to the first plosive in the CVC words. Also, C2 refers to the second plosives in the words.

T-tests, with the tails 2 and type 2 , are performed to see the significance of the difference, using the standard $p$ $\leq$ 0.05.The VOT and vowel duration obtained from the Praat program are converted to milliseconds.

\section{B. RESULTS AND DISCUSSION}

a. The results of the first 4 sound files, 8 test words in each file, one token.

1) The means and Standard Deviations

The following tables show the means and the standard deviationsof the Vowel Duration and VOTof each set in milliseconds.

Table 1. Mean and Standard Deviation of the Vowel Duration Followed by Voiceless and Voiced Plosives

\begin{tabular}{|l|c|c|}
\hline & C V C $_{\text {[-voice] }}$ & C V C $_{\text {[+voice] }}$ \\
\hline Mean & 129.05 & 193.85 \\
\hline Standard Deviation & 37.21 & 34.42 \\
\hline
\end{tabular}

Table 2. Mean and Standard Deviation of the Vowel Duration Preceded by Voiceless and Voiced Plosives

\begin{tabular}{|l|c|c|}
\hline & $\mathrm{C}_{[\text {-voice] }} \mathrm{V} \mathrm{C}$ & $\mathrm{C}_{[\text {tvoice] }} \mathrm{V} \mathrm{C}$ \\
\hline Mean & 153.22 & 169.67 \\
\hline Standard Deviation & 55.53 & 39.76 \\
\hline
\end{tabular}

The results show that the voicing of the following plosives affects the vowel duration, while the voicing of the preceding plosives does not affect the vowel duration. This is confirmed by the t-test that show the difference between the means of the following plosives that are different in voicing is $1.69 \mathrm{E}-5$ (which means $1.69 \times 10^{-5}$ ), so it is
$<0.05$. While the t-test of the vowel duration between the groups of different voicing of the preceding plosives shows that it is 0.34 , which is not $<0.05$, so it is insignificant.

The following tables show the results of the means and standard deviation of the VOT, of different voicing of the following and preceding plosives. 
Table 3. Mean and Standard Deviation of the VOT of C2 (the Word Ending) by Voiceless and Voiced Plosives

\begin{tabular}{|l|c|c|}
\hline & C V C $_{\text {[-voice] }}$ & C V C $_{\text {[+voice] }}$ \\
\hline Mean & 53.76 & 47.51 \\
\hline Standard Deviation & 43.56 & 40.80 \\
\hline
\end{tabular}

Table 4 Mean and Standard Deviation of the C1 VOT by Voiceless and Voiced Plosives

\begin{tabular}{|l|c|c|}
\hline & $\mathrm{C}_{\text {[-voice] }} \mathrm{V} \mathrm{C}$ & $\mathrm{C}_{\text {[+voice] }} \mathrm{V} \mathrm{C}$ \\
\hline Mean & 89.56 & 11.71 \\
\hline Standard Deviation & 17.75 & 5.91 \\
\hline
\end{tabular}

The results show that it is the voicing of the $\mathrm{C}_{1}$ plosives that affect the VOT. The following plosives do not affect the VOT of the preceding plosives. This result is also confirmed by the test of significance of the means. The t-test of the means of the different voicing of the preceding plosives (or the $\mathrm{C} 1$ ) is $1.066 \mathrm{E}-16$ (or $1.066 \mathrm{X} 10^{-}$ $\left.{ }^{16}\right)$, which is much smaller than 0.05 , and it means the difference is significant. While the calculation of the t-test of the means of the
VOT of the different voicing of the following plosives is 0.68 , which is not smaller than 0.05 , and it means it is not significant.

\section{b. The results of the first 4 sound files, 1 test word in each file, ten tokens.}

The following two tables show the results of the data on the vowel durations for plosives of different voicing, both following and preceding them.

Table 5. Mean and Standard Deviation of the Vowel Duration Followed by Voiceless and Voiced Plosives

\begin{tabular}{|l|c|c|}
\hline & C V C $_{[\text {-voice }]}$ & C V C $_{[\text {-voice }]}$ \\
\hline Mean & 96.08 & 211.40 \\
\hline Standard Deviation & 16.22 & 34.10 \\
\hline
\end{tabular}

Table 6. Mean and Standard Deviation of the Vowel Duration Preceded by Voiceless and Voiced Plosives

\begin{tabular}{|l|c|c|}
\hline & $\mathrm{C}_{\text {[-voice] }} \mathrm{V} \mathrm{C}$ & $\mathrm{C}_{\text {[+voice] }} \mathrm{V} \mathrm{C}$ \\
\hline Mean & 151.8 & 152.75 \\
\hline Standard Deviation & 61.17 & 68.48 \\
\hline
\end{tabular}

The results in these sets of sound files confirm the previous results. The voicing the following plosives affect significantly the vowel duration, while the voicing of the preceding plosives does not affect it. The result of the t-test shows that the different voicing of the following plosives is 5.74E16 (or $5.74 \times 10^{-16}$ ), which is lower than the $0.05 \mathrm{p}$ value. While the t-test of the preceding different voicing of plosives is 0.96 , which is higher than $0.05 \mathrm{p}$ value, and so it means it is not significant. 
The results of the VOT measurement show that the voicing of the preceding plosives significantly affect the values. While the following voicing of the plosives do not show significant effect on the VOT values.

Table 7 Mean and Standard Deviation of the VOT of C2 (the word ending) by Voiceless and Voiced Plosives

\begin{tabular}{|l|c|c|}
\hline & C V C $_{\text {[-voice] }}$ & C V C $_{\text {[+voice] }}$ \\
\hline Mean & 34.80 & 37.45 \\
\hline Standard Deviation & 24.62 & 18.03 \\
\hline
\end{tabular}

Table 8 Mean and Standard Deviation of the C1 VOT by Voiceless and Voiced Plosives

\begin{tabular}{|l|c|c|}
\hline & $\mathrm{C}_{\text {[-voice] }} \mathrm{V} \mathrm{C}$ & $\mathrm{C}_{\text {[+voice] }} \mathrm{V} \mathrm{C}$ \\
\hline Mean & 52.34 & 19.91 \\
\hline Standard Deviation & 13.54 & 14.069 \\
\hline
\end{tabular}

The t-test of the different groups of preceding voicing is $6.58 \mathrm{E}-09$ (or $6.58 \mathrm{X} 10$ ${ }^{-9}$ ), which is smaller than the $\mathrm{p}$ value 0.05 , and so it is significant. The t-test of the VOT values for different voicing of following plosives is 0.70 , which is higher than 0.05 , and it means it is insignificant.

All the results above show that the preliminary hypothesis, i.e. that voicing of following plosives affects the length of the vowels, indicated by the vowel duration, and VOT is affected by the voicing of the preceding plosives, not the following plosives, is proven to be correct.

Ohala (1997) in his paper compared the contemporary view of the relation between phonetics and phonology with earlier attitudes on the matter. Phonetics and phonology did not exist as separate disciplines in earlier centuries. Ohala looks at the relation between phonetics and phonology as the relation between the domains of the study, and in his opinion, phonology has to be seen as the discipline that tries to answer questions about spoken language by employing the methods, data, and theories of phonetics, as well as psychology, social sciences, history, ethology, etc.He also points out that a phonetic account of how natural sound patterns will make a convincing explanatory scenario.
He mentions the common practice within phonetics of making a given measurement, such as vowel duration on multiple tokens, like the one in this lab, is evidence of the integration of phonetics and phonology and that phonology can benefit from phonetic studies.

\section{CONCLUSIONS}

The results of this study show that the voicing of the following plosives affects the vowel duration, while the voicing of the preceding plosives does not affect the vowel duration. The results also show that it is the voicing of the $\mathrm{C}_{1}$ plosives that affect the VOT. The word-ending plosives do not affect the VOT of the preceding plosives.

The current study shows the standard deviations but does not discuss further the implication of the deviations. Further study can provide analysis on it.More sample words with not only voiced and voiceless plosives, but also voiced and voiceless fricatives and affricates can be taken to provide further evidence if voiced and voiceless obstruents, not only stops or plosives, have the same pattern as the results of this study. This study is on English vowel duration and VOT affected by the following and preceding stops. A further study can be done to compare the results of the effects with another language. 


\section{REFERENCES}

Ohala, John J. 1997. "The Relation Between Phonetics and Phonology". The Handbook of Phonetic Sciences. William J Hardcastle; John Laver (ed).
Oxford, UK ; Malden, Mass. : Blackwell Publishers.

Source of sound files:

Class website: http://udel.edu/ heinz/ classes/2012/4-633/log.html 
Appendix 1: The calculations of the second set of sound files

\begin{tabular}{|c|c|c|c|c|c|}
\hline words & VOT in ms & $\begin{array}{l}\text { Vowel Length } \\
\text { in } \mathrm{ms}\end{array}$ & & & \\
\hline tuck1 & 50.3 & 103.3 & Mean & & \\
\hline tuck2 & 52.3 & 122.5 & VOT -voice C1 & 52.338 & \\
\hline tuck3 & 54.93 & 118.04 & VOT + voice C1 & 19.914 & \\
\hline tuck4 & 56.1 & 93.49 & & & \\
\hline tuck5 & 51.7 & 100.9 & Mean & & \\
\hline tuck6 & 52.91 & 68.29 & Vowel Length & & \\
\hline tuck7 & 54.09 & 80.83 & VL C2 -voice & 96.081 & \\
\hline tuck8 & 86.49 & 83.34 & VL C2 +voice & 211.4042105 & \\
\hline tuck9 & 70.14 & 95.98 & & & \\
\hline \multirow[t]{3}{*}{ tuck10 } & 41.22 & 103.98 & Mean & & \\
\hline & & & VOT -voice C2 & 34.8025 & \\
\hline & & & VOT +voice C2 & 37.4495 & \\
\hline tug1 & 68.28 & 181.2 & & & \\
\hline tug2 & 48.58 & 187.77 & Standard Dev & & \\
\hline tug3 & 46.41 & 171.61 & VOT -voice C1 & 13.54345155 & \\
\hline tug4 & 45.3 & 171.62 & VOT +voice C1 & 14.06898358 & \\
\hline tug5 & 73.46 & 206.49 & & & \\
\hline tug6 & 32.75 & 195.57 & & & \\
\hline tug7 & 38.71 & 211.45 & Standard Dev & & \\
\hline tug8 & 33.75 & 255.13 & Vowel Length & & \\
\hline tug9 & 41.69 & 252.21 & VL C2 -voice & 16.22142829 & \\
\hline \multirow[t]{2}{*}{ tug10 } & 47.65 & 232.3 & VL C2 +voice & 34.09629425 & \\
\hline & & & Mean & & \\
\hline duck1 & 24.55 & 110.7 & VL C1-voice & 151.8 & \\
\hline duck2 & 8.57 & 81.46 & VL C1 +voice & 152.7526316 & \\
\hline duck3 & 11.3 & 99 & & & \\
\hline duck4 & 10.53 & 75.52 & Stand Dev & & \\
\hline duck5 & 14.42 & 102.13 & VOT C2 -voice & 24.61633409 & \\
\hline duck6 & 7.79 & 108.75 & VOT C2 +voice & 18.02869598 & \\
\hline
\end{tabular}




\begin{tabular}{|c|c|c|c|c|c|}
\hline duck7 & 14.03 & 117.72 & & & \\
\hline duck8 & 15.98 & 98.61 & Stand Dev & & \\
\hline duck9 & 9.35 & 91.99 & VL C1 -voice & 61.16815004 & \\
\hline duck10 & 9.35 & 65.09 & VL C1 +voice & 68.48023031 & \\
\hline & & & $\begin{array}{l}\text { T Test VOT } \\
\text { (Voicing) }\end{array}$ & $6.58548 \mathrm{E}-09$ & significant \\
\hline dug1 & 9.7 & 139.11 & $\begin{array}{l}\text { preceded by } \\
\text { +-voice }\end{array}$ & & \\
\hline dug2 & 54.9 & 194.11 & $\begin{array}{l}\text { T Test Vowel } \\
\text { length }\end{array}$ & $5.73803 \mathrm{E}-16$ & significant \\
\hline dug3 & 49.33 & $207 .-5$ & $\begin{array}{l}\text { followed by } \\
\text { +-voice }\end{array}$ & & \\
\hline dug4 & 37.2 & 208.67 & $\begin{array}{l}\text { T Test VOT } \\
\text { (Voicing) }\end{array}$ & & \\
\hline dug5 & 29.11 & 253.96 & $\begin{array}{l}\text { followed by } \\
\text { +-voice }\end{array}$ & 0.700205483 & insignificant \\
\hline dug6 & 8.89 & 200.58 & $\begin{array}{l}\mathrm{T} \text { Test Vowel } \\
\text { Length }\end{array}$ & & \\
\hline dug7 & 21.02 & 234.55 & $\begin{array}{l}\text { preceded by } \\
\text { +-voice }\end{array}$ & 0.963661394 & insignificant \\
\hline dug8 & 34.77 & 214.33 & & & \\
\hline dug9 & 12.94 & 236.69 & & & \\
\hline dug10 & 14.55 & 269.33 & & & \\
\hline
\end{tabular}


Appendix 2: Samples of the measurement of the VOT and Vowel Duration

tuck

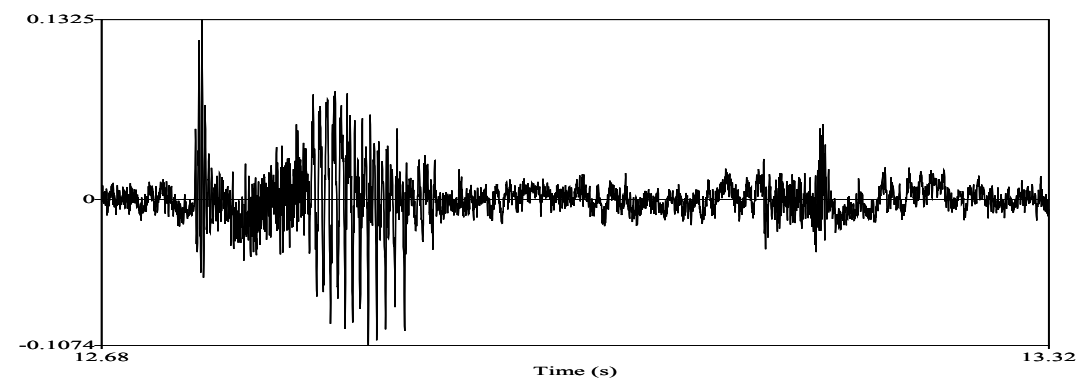

$<$ VOT--><V Duration $>$

tug

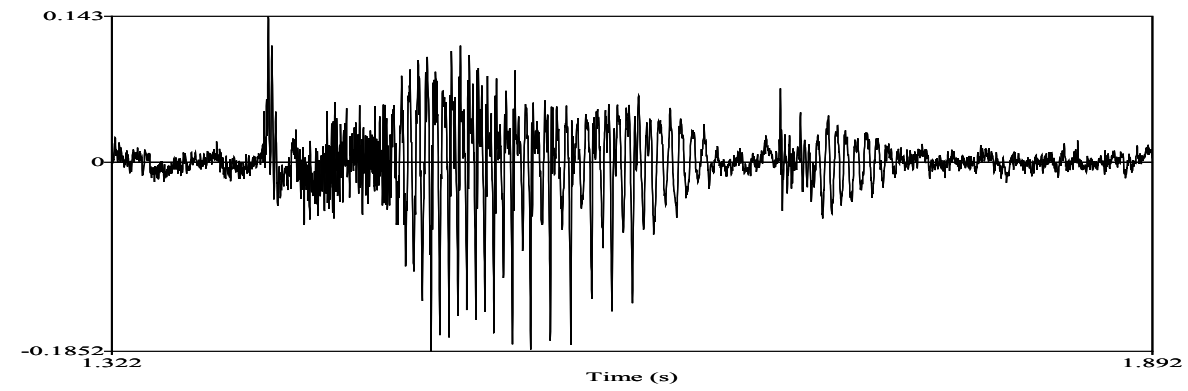

<VOT------><----------Vowel Duration--------->

duck

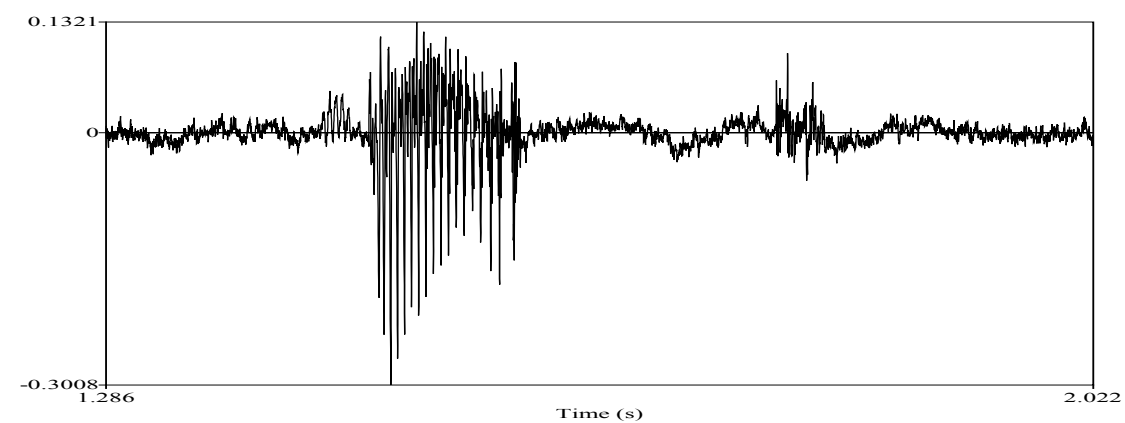

$<$ VOT $><$ Vowel Duration $>$

dug

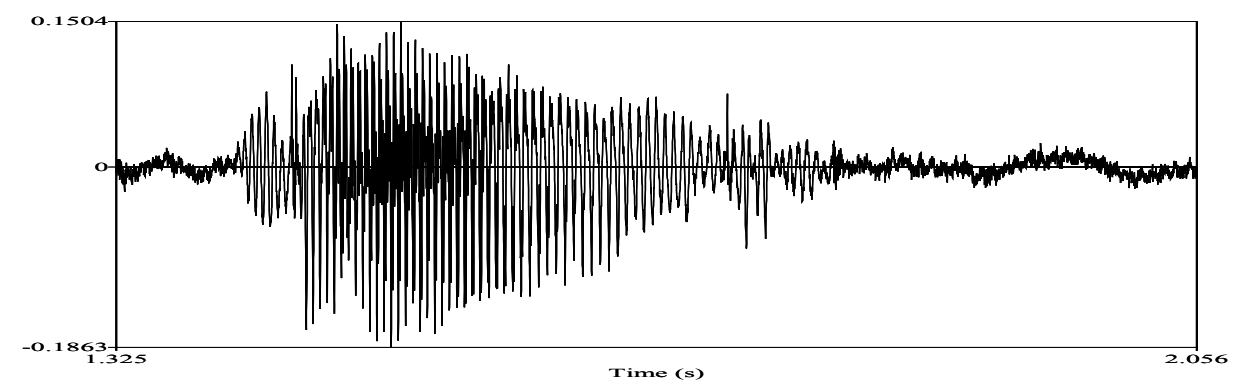

$<$ VOT ><--------Vowel Duration------> 